\title{
La familia frente a los nuevos desafíos a la luz del Sínodo ${ }^{1}$
}

\author{
Gerhard Ludwig Cardenal Müller \\ PREFECTO DE LA CONGREGACIÓN PARA LA DOCTRINA DE LA FE
}

\section{LA FAMILIA Y LA EVANGELIZACIÓN EN EL SÍNODO DE OBISPOS DE 2015}

La Iglesia universal ha vivido durante el pasado mes de octubre un ejercicio privilegiado de gobierno en referencia al munus petrinum. Al respecto, si todo Sínodo de Obispos, colegio permanente convocado de manera regular (cf. can. 342 CIC), es un instrumento de comunión importante para la vida de la Iglesia universal y de las Iglesias particulares, esta XIV Asamblea General Ordinaria del Sínodo de los Obispos, sorprendentemente, ha sido convertida por los mass media mundiales en acontecimiento mediático de primera magnitud, objeto de apasionados debates paralelos a los mantenidos en el Aula Sinodal y de lecturas ideológicas de todo orden.

Durante tres semanas, 258 Padres Sinodales de los cinco continentes han sido convocados por el Papa Francisco para colaborar colegialmente con él y entre sí en el estudio de "los desafíos pastorales de la familia en el contexto de la evangelización" ${ }^{2}$, expresando así la sollicitudo omnium ecclesiarum propia de todo obispo (modo expresivo y operativo en el ejercicio pastoral de todo obispo que pone en evidencia el nexo íntimo que existe entre la colegialidad y el primado ${ }^{3}$ ) y el affectus collegialis de los obispos entre sí (disposición interior de todo obispo tendente a

Esta conferencia fue pronunciada en la Pontificia Universidad Católica de Chile el lunes 9 de noviembre de 2015.

2 Cf. Sínodo de los Obispos, Documento preparatorio de la III Asamblea General Extraordinaria, 8 de octubre de 2013.

3 Cf. S. Juan Pablo II, Discurso al Consejo de la Secretaría General del Sínodo de los Obispos, 30 de abril de 1983. 
mantener vivo el espíritu colegial en el ejercicio concreto de la caritas pastoralis $\left.{ }^{4}\right)$.

La nuestra es una época de crisis, de revisión de las configuraciones precedentes en todos los aspectos fundamentales de la vida, también del matrimonio. No es la primera, ni será la última época de crisis, aunque la de hoy es la crisis del modelo antropológico que inspiró la concepción del matrimonio y su proceso de institucionalización jurídica en Occidente.

Por un lado, el matrimonio tiende a "desnaturalizarse", por lo que no se le considera ya como una institución de derecho natural, sino como un producto ideológico-religioso y una mera construcción institucional de la legalidad vigente: desmontar el presunto "modelo tradicional" de matrimonio y de familia aparece como exigencia del progreso y de adaptación a los nuevos modelos de sociedad. La misma creencia de que existen varios "matrimonios" es expresión de que esta institución ha dejado de ser para muchos una realidad para convertirse en una idea o, peor aún, en una opinión subjetiva.

Por otro, la cultura occidental ha "privatizado" el matrimonio, por lo que las normas que lo definen y que regulan sus conflictos dejan de responder a valores públicos y objetivos, indisponibles a las partes, para inspirarse en criterios y valores afectivos como ocurre con el sentimiento de felicidad subjetivo de cada cónyuge, considerado singular y unilateralmente. Cada vez parecen ser más irreconciliables la libertad y la autenticidad del amor y las exigencias institucionales del matrimonio: la indisolubilidad del vínculo naufraga a costa de la aceptación general y acrítica del divorcio; la fidelidad y la exclusividad no se consideran rasgos definidores del vínculo, sino situaciones afectivas que pertenecen a la conciencia privada del individuo; la generación y educación de la prole son vistas como opciones privadas y libres, no como componentes definidores del matrimonio; hasta la misma heterosexualidad como elemento esencial del matrimonio, también es puesta en discusión. Paradójicamente, mientras el matrimonio se vacía y se equipara a la unión de hecho, cualquier forma de sexualidad reclama el derecho a ser reconocida legalmente como "matrimonio", siendo el punto final del recorrido de esta "privatización” del matrimonio la legalización del

\footnotetext{
Cf. S. Juan Pablo II, Discurso a los Cardenales, a la Curia y a la Prelatura romana
} para la presentación de las felicitaciones de la Navidad, 20 de diciembre de 1990. 
simple rito formal nupcial, en tanto que instrumento para conseguir la felicidad personal. En esta perspectiva egocéntrico-individualista, la pareja-instrumento se sostiene mientras cada uno de sus componentes logre su cuota de satisfacción individual's

En el mencionado documento preparatorio de 2013 se subrayaba el desafío pastoral que supone la actual crisis social y espiritual que afecta a tantas familias en un mundo globalizado. Se exponían numerosas situaciones que exigen con urgencia la atención y el compromiso pastoral de la Iglesia, como son los matrimonios mixtos, la familia monoparental, la poligamia, el sistema de castas, la falta de compromiso, el pluralismo relativista en el concepción del matrimonio, el desprecio por la estabilidad y la fidelidad del pacto matrimonial, la maternidad subrogada, las nuevas interpretaciones de los derechos humanos. Sin embargo, se subrayaba "en ámbito más estrictamente eclesial, la debilitación o el abandono de fe en la sacramentalidad del matrimonio y en el poder terapéutico de la penitencia sacramental". Por todos estos motivos, se confiaba a la caridad de los pastores el discernimiento de cómo presentar la buena noticia del amor divino al mundo de hoy, de forma clara e incisiva, para que "el tesoro de la revelación encomendado a la Iglesia vaya llenando los corazones de los hombres" (DV26).

Dos años después, apenas concluido el Sínodo y antes de que el Santo Padre acoja los arduos trabajos plasmados en la Relación Final que le fue presentada a este último el 24 de octubre de 2015, podemos afirmar que el debate surgido a raíz del pasado Sínodo ha puesto de relieve la necesidad de profundizar con mayor agudeza teológica la indisolubilidad del matrimonio sacramental. La Iglesia de hoy, más que nunca, está llamada a anunciar la belleza del matrimonio indisoluble ante un mundo sediento de verdad, explicitando a todos la fuerza de la gracia del sacramento.

\section{LA CRISIS DE LA SACRAMENTALIDAD PROPIA DE LA MODERNIDAD}

Tal como he señalado recientemente en diversas ocasiones, considero que el principio sacramental y, en concreto, la concepción sacramental del matrimonio, atraviesan hoy una crisis profunda, de largo alcance y de consecuencias imprevisibles.

\footnotetext{
Cf. Pedro-Juan Viladrich, "Matrimonio" en Diccionario General de Derecho Canónico, Volumen V, Pamplona 2012, 310-312.
} 
"El hombre se encuentra en un camino de búsqueda, humanamente interminable: búsqueda de la verdad y búsqueda de una persona de quien fiarse" (San Juan Pablo II, carta encíclica Fides et Ratio, 33). La exploración apasionada de la verdad, junto al deseo de belleza y la nostalgia del bien, han definido siempre lo radicalmente humano y, por tanto, la experiencia cristiana desde sus mismos inicios. Por el contrario, cuando se ha partido de una falsa antropología, han resultado consecuencias terribles. El siglo XX, por poner un ejemplo cercano a nosotros, es fiel testigo de ello. Como dije recientemente, "si se calla que el ser humano se define en base a la relación con Dios, origen y fin de la persona, el resultado es el inmanentismo más absoluto: es un callejón sin salida, en el cual el hombre se ve obligado a perfeccionarse solamente con los medios creados, entre los cuales la sexualidad aparece solo como un ídolo" ${ }^{6}$.

Los primeros pensadores cristianos, en su encuentro fecundo con la filosofía helenística, lograron unir la tradición judía y la greco-latina. En feliz expresión de Benedicto XVI, "siguiendo una necesidad intrínseca derivada de la naturaleza de su fe" ", introdujeron en el pensamiento occidental una nueva lógica, la de la racionalidad sacramental, por la que toda persona, creada a imagen y semejanza de Dios (cf. Gen 1, 26), alcanza su plenitud aceptando a Cristo como centro y clave de toda la vida: Christo nibil omnino praeponere ${ }^{8}$. Acoger tal gracia "que vale más que la vida" (Sal 63, 3), hace posible "no vivir ya para nosotros mismos, sino para Aquel que por nosotros murió y resucitó" (2 Cor 5, 15). Cuando yo logro examinar todos los aspectos de mi vida a la luz de la cruz y de la resurrección de Cristo, me doy cuenta que puedo enfrentarme a cualquier dificultad.

El bautizado, por tanto, es aquel que vive la "lógica del don" en la realidad concreta en la que desenvuelve su vida, espacio rico de matices puesto que es un lugar sagrado en el que Dios manifiesta su verdad y su obra ("sácate tus sandalias porque el lugar que pisas es tierra sagrada": Ex 3, 5). La naturaleza, transparencia del Logos eterno que se ha revelado en nuestra carne (cf. Jn 1, 14) y que vive la presencia fiel de este hasta el fin de los tiempos (cf. $M t 28,20$ ), se concibe toda ella abierta

6 Gerhard L. Müller, La esperanza de la familia, 69.

7 Benedicto XVI, Encuentro con el mundo de la cultura en el Collège des Bernardins, 28 de enero de 2007.

8 S. Benito, Regla, LXII, 11. 
constitutivamente a la gracia, sin que sea posible someter en compartimientos estancos "lo natural" y "lo sobrenatural". En esta armónica weltanschauung o cosmovisión, accesible desde la humildad no por una "razón pura o natural" sino por una razón perfeccionada e iluminada por la $\mathrm{fe}^{9}$, no cabe ningún falso dualismo o reductivismo.

Sin embargo, paradójicamente casi coincidiendo en el tiempo con la gran síntesis de teología cristiana y filosofía que realizó San Tomás de Aquino, la civilización occidental ha asistido a una fragmentación de la tradición cristiana. De hecho, los tiempos que vivimos y sus retos serían incomprensibles si no consideráramos que somos "hijos de la modernidad". La pérdida del sentido de la analogía del ser y el nominalismo propios de la racionalidad moderna han reducido al hombre a ser un simple "individuo" concebido aisladamente, un absoluto que habita un mundo simple regido por la "lógica del poder" y del interés. Un ser humano cuyo "estado natural" es el de la continua guerra de todos contra todos y que, por tanto, solo puede ser redimido por el Leviatán, o sea, el Estado ${ }^{10}$. Una realidad que es concebida a partir del mercado, el único gran paradigma incontestado en nuestro tiempo. Tanto tienes, tanto vales. En esta modernidad, las acciones humanas, ajenas a la lógica del don, solo parecen considerarse razonables cuando cada uno sigue su propio interés.

No es casual que el mundo adopte a los ojos de nuestros coetáneos una imagen fisicista y mecanicista, en el que la materia es solo una cantidad y lo singular una simple función. No debe sorprendernos tampoco que el ser humano no logre ya ver el mundo material y las cosas concretas como medios que le ayudan a reconocer su relación con el horizonte global y el fundamento de todo ser.

Sin embargo, la vida real contradice una y otra vez esta imposición sutilmente tiránica. Cualquiera de nosotros siente en algún momento la nostalgia de la verdad, de la auténtica belleza, del bien que puede ser hasta heroico. Cuando recibimos más de lo que nos era debido, cuando somos capaces de dar con una generosidad que incluso nos sorprende a nosotros mismos, entendemos que el don de la vida tiene en sí una racionalidad intrínseca tal, que logra hacernos salir de nuestras comodidades y nos pone en camino.

9 Cf. Benedicto XVI, Angelus, 28 de enero de 2007.

10 Cf. T. Hobbes, Leviatán, cap. XIII. 
Al respecto, la Eucaristía es la gran provocación a la "racionalidad" que nace del Iluminismo, puesto que anticipando "los cielos nuevos y la tierra nueva", proclama sin ambigüedad alguna que lo definitivo ha entrado en la historia y que permanecerá en ella siempre, presentando el ser como don gratuito que llama a vivir en comunión. Esta ontología sostiene una antropología y una ética verdaderas, atrayentes, puesto que la llaman a vivir la vida recibida desde la categoría del don y de la gratuidad, iluminando así la vida social, la vida económica y, cómo no, la vida personal y matrimonial. No es casual, por tanto, que el lenguaje eucarístico sea un lenguaje nupcial.

Al respecto, desde la llamada "simbólica del ser" (Seinssymbolik), podemos afirmar que el símbolo no es un sistema arbitrariamente construido y desgajado del resto de la realidad. El ser, como actualidad general del ente particular, puede ser conocido en su racionalidad interna puesto que se expresa en la fragmentación limitadora del ente particular. Considerado como ente "para sí", manifiesta unos atributos y rasgos que son distintos de sí, como ocurre cuando percibimos lo espiritual en lo material o el alma en el cuerpo (o mejor dicho, el alma como cuerpo). De ahí que podamos concluir que el mundo, en su existencia concreta, tiene la capacidad simbólica de expresar "el poder y la divinidad eternos de Dios", "haciéndose asequible por la razón a las criaturas" (cf. Rom 1, 20; Hch 17, 24; Sap 13, 1-9; Ecl 17, 8 ss.).

Cuando ya no es posible entender un símbolo materialmente estructurado como medio y expresión de la realidad trascendente, también los sacramentos se tornan impenetrables. De ahí la importancia de clarificar filosófica y ontológicamente la categoría del símbolo, en tanto que fundamento de las demás vías de acceso a la realidad, para poder fundar una teología de los sacramentos sólida.

\section{LA VIDA DEL HOMBRE ES, TODA ELLA, SIMBÓLICA}

El ser humano, como cualquier otro ente, es llamado a la existencia histórica por Dios. Sin embargo, su naturaleza corpóreo-espiritual deviene fundamento dinámico de su posibilidad de autocomunicarse y de estar personalmente en otros en su ser. La persona, por tanto, no es primero un espíritu puro que en un segundo momento se comunica a sí mismo y sale al encuentro de otras personas. Más bien, la autoexpresión y comunicación interpersonal en la materia corporal sexuada es el fac- 
tor constitutivo esenciales del espíritu personal y de la libertad de todo hombre y mujer.

El cuerpo es así "símbolo real" (Realsymbol) que el alma actualiza, materia prima o pura posibilidad. Siendo condición de todo encuentro interpersonal en el espacio y no obstáculo entre dos almas, posibilita también la relación personal y directa con Dios, dado que no es posible una tal relación en un entorno meramente espiritual, ajeno a la naturaleza creada. Por otra parte, es también autoexpresión estructurada en el tiempo. Nuestra propia biografía, manifestación de nuestra actualidad personal completa, muestra acontecimientos especiales que, en sí, son símbolos clave y puntos de inflexión de nuestra existencia particular.

Somos concebidos y nacemos. Más allá de su positividad, estos dos eventos poseen una dimensión simbólica natural que expresamos en el sacramento del bautismo, puesto que en el comienzo de un espíritu finito en el mundo existe una remisión al origen absoluto del ser humano en Dios.

También crecemos. En el desarrollo personal encontramos el símbolo natural de la estructura de lo temporal, de lo histórico, en camino hacia la consumación. Por ello es importante representar simbólicamente tal maduración acompañada y fortalecida por el Espíritu Santo, tal como ocurre en la confirmación.

Nos alimentamos. La ingesta de alimentos habla de la relación constitutiva del hombre con la materia, que permite mantener la fuerza vital. Toda comida, por tanto, posee en sí un simbolismo natural que, vivido en la Eucaristía, remite a una realidad ulterior, como es la recepción de Dios del sentido absoluto de la propia vida.

Intuimos, por tanto, que la liturgia cristiana y los sacramentos no son expresión de una iniciativa humana para obtener algo de la divinidad o para ganarse su favor. El culto cristiano presupone la reconciliación con Dios, obrada por El (cf. 2 Cor 5, 20) y es la participación simbólica y comunión en la entrega de Cristo al Padre en el Espíritu Santo (cf. Gal 4, 4-6; 1 Cor 10, 16ss, 11, 24ss).

\section{EL SACRAMENTO DEL MATRIMONIO}

No existen indicaciones claras ni precisas sobre la existencia de una verdadera ni propia celebración litúrgica del matrimonio durante los primeros siglos de la Iglesia. Los cristianos "se casan como todos los 
demás, como los demás tienen hijos, pero no abortan, ni abandonan a los recién nacidos, tienen en común la mesa pero no el lecho" (Carta a Diogneto $)^{11}$.

Inmersos en un proceso de progresiva "eclesialización” del matrimonio a raíz de la oficialización en el Imperio del cristianismo, los Padres adoptaron una inequívoca defensa de esta institución: por un lado, frente a una sexualidad promiscua, vivida sin control y legitimada en el ámbito religioso con la prostitución sagrada de los templos y por otro, frente a una ética estoica y maniquea, la cual identifica la materia y el placer como el principio del mal, despreciando así la sexualidad y la unión conyugal.

Como consecuencia, la reflexión teológica de los Padres se dirigió a resaltar la riqueza y belleza de la realidad matrimonial en el proyecto de la Creación (el matrimonio es una realidad buena para la pareja humana y fuente de vida, dado que refleja el misterio de Dios, amor y vida) y en el proyecto de la Redención (el matrimonio entre bautizados está envuelto en el misterio de Dios en Cristo Jesús, quien por pura gracia, lo devuelve a su dignidad original, obscurecida por el pecado a lo largo de la historia).

La fijación dogmática del matrimonio como uno de los siete sacramentos de la nueva ley tuvo lugar en el Concilio de Trento (cf. DS 1800; $1891)^{12}$. Comunidad de vida entre un hombre y una mujer bautizados, el signo nupcial es comunión integral, exclusiva y personal libremente constituida que tiene la virtualidad de reflejar la alianza de Cristo con su Iglesia $(E f 5,32, D S 1327)$ y de comunicar eficazmente la gracia santificante. Es, en palabras de San Juan Pablo II, "símbolo real de la nueva y eterna alianza, sancionada con la sangre de Jesucristo"13.

Desde una perspectiva dinámica, es decir, atendiendo a los fines, el matrimonio está "ordenado por su misma índole natural al bien de los cónyuges y a la generación y educación de la prole” (can.1055\$1 CIC). Son fines inscritos en una dinámica única, por lo que no es procedente separarlos ni contraponerlos: el primer bien del matrimonio, la unión

\footnotetext{
11 Carta a Diogneto, V. 7; Funk 1, 318.

12 Cf. Concilio de Trento, Ses. 24, Doctrina y cánones sobre el sacramento del matrimonio(11.IX.1563), DS 1797-1812.

13 San Juan Pablo II, ex. ap. Familiaris consortio (22.11.1981), 13.
} 
entre los esposos, humaniza la procreación, por lo que una procreación en la que los padres no son cónyuges o están desunidos es, para los hijos, un mal objetivo.

Los modos de expresar esta ordenación esencial del matrimonio, sin embargo, han variado a lo largo de los siglos. San Agustín, consciente de su vida licenciosa previa a su conversión, consideraba imposible que el hombre pudiera practicar la sexualidad sin caer en el pecado. Sin embargo conocía bien la enseñanza bíblica, la cual destaca la bondad de la unión conyugal por los tres bona que compensan las deficiencias que el hombre corrompido experimenta cuando el placer corporal actúa en detrimento del espíritu: 1) el bien de acoger los hijos y de educarlos para que logren conocer a Dios, amarle y darle culto (bonum prolis); 2) el bien de la fidelidad recíproca, exclusiva y para toda la vida (bonum fidei); 3) el bien de la indisolubilidad y de la indestructibilidad del vínculo sacramental, fundado en la indivisible unidad entre Cristo y la Iglesia y, por tanto, expresión de la dimensión sagrada del matrimonio cristiano (bonum sacramenti). Armonizando la dimensión del vínculo jurídico (vinculum) con el símbolo religioso real (signum), San Agustín pudo llegar a afirmar que el matrimonio, por ser sacramentum-signum de la unión esponsalicia de Cristo con su Iglesia, en tanto que sacramentumvinculum es verdadera y radicalmente indisoluble.

La reflexión teológica medieval posterior, en cambio, tendió a hacer prevalecer el régimen de los fines sobre el de los bienes. Santo Tomás distinguió tres fines, sin jerarquizarlos entre ellos: "el primer fin, la procreación y educación de la prole, compete al matrimonio del hombre en cuanto es animal; el segundo, la mutua fidelidad, en cuanto es hombre; el tercero, el sacramento, en cuanto es fiel cristiano" (S.Th., Suppl., q.65, a.1). Solo el can. 1013 CIC 1917 estableció una jerarquía de fines (la procreación y educación de la prole es fin primario, mientras que la mutua ayuda es fin secundario), mientras que a partir del Vaticano II los fines se expresaron en paridad, por lo que los aspectos unitivo y procreador se hacen responder de modo simultáneo y radical a la significación más profunda de la sexualidad y del matrimonio ${ }^{14}$.

14 Cf. GS 50; PaOlo VI, enc. Humanae vitae (25.7.1968) n. 12; Juan Pablo II, ex. ap. Familiaris consortio (22.11.1981) n. 32; CCE, n. 2363; can. $1055 \$ 1$ CIC. 
Considerado estáticamente y en íntima relación con los fines antes señalados, el matrimonio goza de unas propiedades esenciales: "las propiedades esenciales del matrimonio son la unidad y la indisolubilidad, que en el matrimonio cristiano alcanzan una particular firmeza por razón del sacramento" (can. 1056 CIC). El matrimonio puede tener muchas propiedades, pero la unidad y la indisolubilidad son las únicas que se derivan de su esencia misma en tanto que vínculo. Son, por tanto, predicables de toda relación matrimonial (de todo matrimonio in facto esse), porque corresponden al matrimonio natural.

La unidad expresa que el vínculo no es multiplicable, porque exige la totalidad de la donación de lo masculino o de lo femenino al otro cónyuge. Por otra parte, los fines del matrimonio requieren igualmente tal unidad, dado que el bien de la prole y el bien de los cónyuges exigen la exclusividad del vínculo y una donación íntegra y fiel.

La indisolubilidad expresa que el pacto conyugal compromete la estructura ontológica de la persona y no solamente su proceder funcional. Por tanto, no cabe un compromiso que perdure menos que las personas que establecen tal pacto: mientras duran ambas personas in hoc saeculo, dura la relación. Por otra parte, también el bien de los cónyuges y el bien de la prole demandan la totalidad temporal sin paliativos ni excepciones.

Aunque sea posible interrumpir la comunidad física de vida entre los esposos, "no es lícito contraer otro matrimonio, comoquiera que el vínculo del matrimonio legítimamente contraído es perpetuo" ( $D H 1327)$, por la correspondencia que tal vínculo, indisoluble en vida, tiene con el carácter (res et sacramentum) impreso en el bautismo, en la confirmación y en el sacramento del orden. Al respecto, 1) aunque el matrimonio no imprime carácter y es reiterable, es un sacramento permanente; 2) por otra parte, el matrimonio que se convierte en sacramento de salvación es el "matrimonio del principio" $(M t 19,8)$, natural, evidenciado por la razón y elevado por Cristo como signo y medio de salvación: "es precisamente la realidad creada lo que es un gran misterio con respecto a Cristo y a la Iglesia” (San Juan Pablo II ${ }^{15}$; 3) finalmente, porque la condición bautismal es la única relevante a efectos de la sacramentalidad, y no otros elementos extrínsecos, la alianza matrimonial y el sacramento son inseparables entre dos bautizados por voluntad divina (cf. can. $1055 \$ 2$ CIC), pues el designio creador

15 San Juan Pablo II, Discurso a la Rota Romana (1.II.2001), 8. 
sobre el matrimonio se convierte en designio redentor cuando este vínculo es contraído por bautizados.

Se observa en la teología reciente una tendencia a una contextualización eclesiológica del matrimonio. A la luz de una antropología personalista y comunicativa de mayor amplitud, el Concilio Vaticano II, especialmente en $G S$ 46-52, describe esta "íntima comunidad de vida y amor" como uno de los actos sacramentales fundamentales de la Iglesia: se observa aquí como el "amor" ha sido incluido entre los fines esenciales del matrimonio, con igual dignidad que a la "generación y educación de la prole". Por otra parte, la opción terminológica bíblica en clave de "alianza" ha implicado relegar una exagerada comprensión jurídica y afirmar su proyección eclesiológica.

Por una parte $L G 11$, al afirmar la vinculación entre los sacramentos y la Iglesia, ha iluminado de un modo nuevo la teología del matrimonio: la sacramentalidad de la unión conyugal se resalta cuanto más se une esta al misterio de la Iglesia ("los esposos, con la fuerza del sacramento del matrimonio, significan y participan el misterio de unidad y amor fecundo entre Cristo y la Iglesia"). Por otra parte, se ha calificado al matrimonio de velut Ecclesia domestica, es decir, de especie de Iglesia doméstica, en la que los padres son los primeros predicadores de la fe y fomentadores de la vocación de sus hijos.

\section{EL COMPROMISO ENTRE LA FIDELIDAD DOCTRINAL Y LA COMPRENSIÓN} PASTORAL

La doctrina acerca de la indisolubilidad del matrimonio es quizás la más incomprendida en nuestros ambientes cada vez más secularizados. En aquellas comunidades en las que se pierden las razones fundamentales de la fe cristiana, una pertenencia meramente convencional a la Iglesia es incapaz de conducir a decisiones definitivas y apenas puede ofrecer el necesario sostén a los que se ven sumergidos en una crisis conyugal. Lo mismo vale, análogamente, para el sacerdocio y la vida consagrada.

De este modo, los pastores constatamos frecuentemente que el ideal de fidelidad entre el hombre y la mujer, fundado en el orden de la Creación, no ha perdido nada de su atractivo. Si preguntamos a cualquier pareja que se acerca a nosotros para contraer matrimonio, tened por seguro que persiguen una relación vital estable y duradera, puesto que ello da respuesta a lo que su corazón anhela y desea en su más íntimo. 
Sin embargo, es también cierto que el "espíritu del mundo" (cf. 1 Cor 2,12 ), la cultura de la modernidad, mundana y pragmática, materialista y hedonista, no ayuda a la comprensión de la sacramentalidad del matrimonio. Se insiste una y otra vez, con palabras y con hechos, que la unión conyugal es una mera "institución secular" (ein rein weltlich Ding, como afirmaba Lutero ${ }^{16}$ ). Se habla de ella como de "ideal humano", deseado aunque inalcanzable para la mayoría. Otros lo califican como "simple bendición”, empobreciendo así la relación humana fundamental, la conyugal, al privarla de la ayuda para que puedan participar de la santidad de Dios. Por otra parte, la indisolubilidad es presentada muy a menudo, con parodias crueles o incluso con discursos pseudocientíficos, como un fardo inhumano e imposible de ser acarreado por toda una vida.

La Iglesia está llamada a "anunciar siempre y en todas partes los principios morales del orden social, pronunciando el juicio sobre cualquier realidad humana en la medida que lo exijan los derechos fundamentales de la persona o la salvación de las almas" (can. 747 CIC y n. 2032 Cat Ig Cat). En tanto que "luz del mundo" (Mt 5, 13-16), debe anunciar a todos, sin miedo, la verdad del ser hombre y mujer, la belleza del matrimonio indisoluble y la fuerza de la gracia del sacramento. La misma biografía de las parejas que con la ayuda de la Gracia se han sido fieles en medio de todos los vaivenes de la vida, proclama que la indisolubilidad es un don que responde a las expectativas más profundas del corazón.

Como "columna y sostén de la verdad" (1 Tim 3, 15), la Iglesia se hace cercana a todos los fieles, pero especialmente a los que más sufren por un fracaso conyugal. Estos son también una de las "periferias existenciales" que subraya el Papa Francisco (Discurso al clero de la diócesis de Roma, 17.9.2013). Por ello necesitan de alguien que les presente en modo íntegro la buena noticia del Resucitado y la certeza de la fuerza victoriosa de la Cruz: "te basta mi gracia" (2 Cor 12, 9).

Nuestras comunidades sufren por los casos dolorosos de "proyectos de vida y amor" fracasados que han herido gravemente a sus protagonistas: la pareja en cuestión, pero también sus hijos, los abuelos, los hermanos y tantos otros. Tales heridas no pueden ser escondidas y menos aún banalizadas. No debieran ser tampoco absolutizadas: las hay más graves y es signo de madurez cristiana admitir que no podemos superar todos

16 Martin Luther, Weimaren Ausgave 30/III, 205. 
los sufrimientos mientras somos peregrinos hacia la casa del Padre, pensando que existe el paraíso en la tierra. Habría que intentar curar tales laceraciones en el Cuerpo de Cristo con la convicción que al igual que las heridas de Jesús, son signos identificativos del Resucitado. Se pueden curar o, al menos sobrellevar, ofreciéndoselas, mediante el buen combate de la fe (cf. $1 \operatorname{Tim} 6,12)$.

Creo que también debemos educarnos todos a mirar con profundo respeto y cariño las cicatrices que quedan después de una herida profunda. Al respecto, la misericordia de Dios no implica un compromiso con el pecado o una dispensa de la ley divina, permitiendo una nueva unión no obstante pervive el anterior cónyuge. Más bien, $M t$ 19, 3-12 ofrece la auténtica hermenéutica de la misericordia, pues esta es la posibilidad que se nos ofrece continuamente para convertirnos, para perseverar en la fidelidad, para aceptar la realidad de la cruz personal en la verdad. El mismo orden sacramental es obra de la misericordia divina: aunque nosotros nos podamos cansar de pedir su perdón, Dios no se cansa nunca de ofrecernos su misericordia. Los pastores, tal como hemos puesto de relieve en el pasado Sínodo, debemos discernir con atención, con misericordia y "por amor a la verdad", todas y cada una de las situaciones personales fruto de un fracaso conyugal que pudieran dar origen a algún tipo de exclusión en el seno de la Iglesia (Relación final, n. 84). Por otra parte, para evitar todo tipo de confusión o subjetivismo pastoral, habrá que tener siempre bien presentes en nuestro horizonte pastoral las enseñanzas del Magisterio de la Iglesia y las orientaciones del Obispo (cf. Familiaris consortio, n.84 y Sacramentum caritatis, n. 29).

La Iglesia tiene el grave deber de testimoniar la belleza y la verdad de la vida conyugal ya en aquellos niños que desde sus primeros pasos en el seno de una comunidad de amor incondicional y generoso, oblativo, se están preparando remotamente al matrimonio sin tan siquiera saberlo. La Iglesia debe acompañar con paciencia y dedicación a los adolescentes y jóvenes que entre las dudas y conflictos propios de su edad, descubren la necesidad de un amor que cubra sus expectativas. La Iglesia debe esforzarse en la acogida a los novios que en su preparación inmediata al matrimonio manifiestan una ilusión y certeza inequívocas de que el paso que están dando les proporcionará, asistidos de la gracia de Dios, la felicidad soñada. Les debe descubrir de modo especial el gran "regalo de bodas" que reciben de Dios, por medio de la Encarnación y por la efu- 
sión del Espíritu Santo: el hecho de que todos, no solo unos escogidos, estamos llamados a participar de la vida divina.

Los cristianos, en modo profético, no podemos permitir que se obscurezca la realidad esencial de este "signo del misterio de unidad y de amor fecundo que une a Cristo y a la Iglesia y del cual participan los esposos" ( $L G 11)$. Tal relación, explícita en Ef5, 32, no puede ser convertida en una mera metáfora, como simple consecuencia explicativa o moral. Al contrario, tal como ha quedado patente en los trabajos del reciente Sínodo del 2015, nos debe llevar a proclamar con claridad y parresía que todo lo significado en el vínculo conyugal, por ser realidad sacramental, tiene una plena efectividad. 